\title{
Article \\ Role of Serum E-Selectin as a Biomarker of Infection Severity in Coronavirus Disease 2019
}

\author{
Alessandra Oliva ${ }^{1, *}++^{\mathbb{D}}$, Emanuele Rando ${ }^{1,2,+}$, Dania Al Ismail ${ }^{1} \mathbb{D}$, Massimiliano De Angelis ${ }^{1}$, \\ Francesca Cancelli ${ }^{1}$, Maria Claudia Miele ${ }^{1}$, Raissa Aronica ${ }^{1}$, Vera Mauro ${ }^{1}$, Federica Di Timoteo ${ }^{1}$ (D), \\ Lorenzo Loffredo $^{3}(\mathbb{D})$ and Claudio M. Mastroianni ${ }^{1}$ (D)
}

1 Department of Public Health and Infectious Diseases, Sapienza University of Rome, Piazzale Aldo Moro 5, 00185 Rome, Italy; rando.1634464@studenti.uniroma1.it (E.R.); dania.alismail@uniroma1.it (D.A.I.); massimiliano.deangelis@uniroma1.it (M.D.A.); francesca.cancelli@uniroma1.it (F.C.); mariaclaudia.miele@uniroma1.it (M.C.M.); raissa.aronica@uniroma1.it (R.A.); vera.mauro@uniroma1.it (V.M.); federica.ditimoteo@uniroma1.it (F.D.T.); claudio.mastroianni@uniroma1.it (C.M.M.)

2 Sapienza School for Advanced Studies (SSAS), Sapienza University of Rome, Viale Regina Elena, 291, 00161 Rome, Italy

3 Department of Clinical, Internal Medicine, Anaesthesiology and Cardiovascular Sciences, Sapienza University of Rome, 00185 Rome, Italy; lorenzo.loffredo@uniroma1.it

* Correspondence: alessandra.oliva@uniroma1.it; Tel.: +39-0649970880

+ These authors equally contributed to the manuscript.

check for updates

Citation: Oliva, A.; Rando, E.; Al Ismail, D.; De Angelis, M.; Cancelli, F.; Miele, M.C.; Aronica, R.; Mauro, V.; Di Timoteo, F.; Loffredo, L.; et al. Role of Serum E-Selectin as a Biomarker of Infection Severity in Coronavirus Disease 2019. J. Clin. Med. 2021, 10, 4018. https:// doi.org/10.3390/jcm10174018

Academic Editor: Vito Racanelli

Received: 11 August 2021

Accepted: 2 September 2021

Published: 6 September 2021

Publisher's Note: MDPI stays neutral with regard to jurisdictional claims in published maps and institutional affiliations.

Copyright: (c) 2021 by the authors. Licensee MDPI, Basel, Switzerland. This article is an open access article distributed under the terms and conditions of the Creative Commons Attribution (CC BY) license (https:/ / creativecommons.org/licenses/by/ $4.0 /)$.

\begin{abstract}
Introduction: E-selectin is a recognized marker of endothelial activation; however, its place in Coronavirus Disease 2019 (COVID-19) has not been fully explored. Aims of the study are to compare sE-selectin values among the Intensive Care Unit (ICU)-admitted and non-admitted, survived and non-survived patients and those with or without thrombosis. Methods: A single-center study of patients with COVID-19 hospitalized at Policlinico Umberto I (Rome) from March to May 2020 was performed. Simple and multiple logistic regression models were developed. Results: One hundred patients were included, with a median age (IQR) of 65 years (58-78). Twenty-nine (29\%) were admitted to ICU, twenty-eight $(28 \%)$ died and nineteen $(19 \%)$ had a thrombotic event. The median value (IQR) of sE-selectin was $26.1 \mathrm{ng} / \mathrm{mL}(18.1-35)$. sE-selectin values did not differ between deceased and survivors $(p=0.06)$ and among patients with or without a thrombotic event $(p=0.22)$. Compared with patients who did not receive ICU treatments, patients requiring ICU care had higher levels of sE-selectin (36.6 vs. $24.1 \mathrm{ng} / \mathrm{mL} ; p<0.001)$. In the multiple logistic regression model, sEselectin levels $>33 \mathrm{ng} / \mathrm{mL}, \mathrm{PaO}_{2} / \mathrm{FiO}_{2}<200$ and $\mathrm{PaO}_{2} / \mathrm{FiO}_{2} 200-300$ were significantly associated with an increased risk of ICU admission. sE-selectin values significantly correlated with a neutrophil count $(\mathrm{R}=0.32(p=0.001))$ and the number of days from the symptoms onset to hospitalization $(\mathrm{R}=0.28(p=0.004))$. Conclusions: sE-selectin levels are predictive of ICU admission in COVID-19 patients. Since data on the relation between sE-selectin and COVID-19 are scarce, this study aims to contribute toward the comprehension of the pathogenic aspects of COVID-19 disease, giving a possible clinical marker able to predict its severity.
\end{abstract}

Keywords: SARS-CoV-2; E-selectin; COVID-19; endothelial activation

\section{Introduction}

On December 2019, a novel coronavirus, named severe acute respiratory syndrome coronavirus 2 (SARS-CoV-2), was identified as a cause of viral pneumonia in the city of Wuhan, China [1]. Since then, the resulting Coronavirus Disease 2019 (COVID-19) has been responsible for a pandemic with a high global burden in terms of morbidity and mortality. COVID-19 can result in a spectrum of forms ranging from a respiratory tract infection to a systemic and severe form characterized by acute respiratory distress syndrome, shock and thrombotic events [2-4]. A great number of these phenomena have been investigated and considerable attention has been paid to the vascular manifestations 
of the disease [5,6]. Multiple studies have illustrated SARS-CoV-2 to target epithelial cells causing local inflammation leading to an imbalance between anti-coagulant and pro-thrombotic factors [7]. E-selectin is a recognized marker of endothelial activation [8] which has been studied in cardiovascular disease [9], but its place in COVID-19 has not completely understood.

Based on these premises, we aim to (i) evaluate the levels of serum E-selectin (sEselectin) in COVID-19-hospitalized patients as marker of endothelial activation and (ii) to correlate the values of this biomarker with the severity of COVID-19, the in-hospital mortality rate and the occurrence of thrombotic events, adding new evidences to the comprehension of some aspects of SARS-CoV-2 infection pathogenesis.

\section{Materials and Methods}

\subsection{Study Population}

Over a 2-month period (March-May 2020), patients with COVID-19 hospitalized at the Azienda Policlinico Umberto I, Sapienza University of Rome, were enrolled in this study. Demographic, clinical and radiological data from all participants were anonymously recorded in an electronic database. Patients were further divided according to disease severity (defined as ICU admission), in-hospital mortality and the occurrence of thrombotic events during hospitalization.

\subsection{Definitions}

Diagnosis of COVID-19 was determined based on suggestive clinical symptoms plus detection of SARS-CoV-2 RNA in nasopharyngeal swab samples by using real-time RT-PCR assay (RealStar SARS-CoV-2 RT-PCR, Altona Diagnostics GmbH, Mörkenstr.12, 22767 Hamburg, Germany). All tests and procedures were performed following the manufacturers' protocols. Disease severity was defined as ICU admission over hospitalization and included need for orotracheal intubation, severe respiratory distress or shock. Arterial and/or venous thrombotic/embolic events included, among others, pulmonary thrombo-embolism, myocardial infarction, acute brain ischemia and acute limb ischemia. Thrombotic/embolic events were defined as the appearance of new ischemic/embolic events diagnosed as follows: (1) pulmonary thrombo-embolism by lung computed tomography (CT) scan [10]; (2) myocardial infarction by EKG changes associated with enhanced markers of cell necrosis [11]; (3) acute brain ischemia by onset of new focal neurological signs and symptoms and confirmed, whenever possible, by magnetic resonance or CT imaging [12]; (4) acute limb ischemia [13].

\subsection{Marker of Endothelial Activation: sE-Selectin}

For each subject, whole blood samples were collected at hospital admission (T0). Ten milliliters of whole blood were collected by venipuncture in Vacutainer tubes containing ethylene-diamine-tetra-acetic acid (EDTA) (BD Biosciences, San Jose, CA, USA) at each study visit. Plasma was immediately separated by centrifugation at $2000 \mathrm{rpm}$ for $10 \mathrm{~min}$ and further stored at $-80^{\circ} \mathrm{C}$ until the assays were performed. Serum E-selectin levels were evaluated using enzyme-linked immunosorbent assays in plasma, according to manufacturers' instructions. Values of sE-selectin were expressed as $\mathrm{ng} / \mathrm{mL}$ (sample diluted 1:10). The study protocol was approved by the local Ethics Committee (ID Prot. 298/2020).

\subsection{Statistical Analysis}

The primary analysis aimed to investigate clinical and laboratory characteristics in two groups defined as ICU admission vs. non-ICU admission. Continuous variables were described using median and interquartile ranges, categorical variables using frequencies and percentages. Wilcoxon rank sum test was used to compare continuous variables and $\chi 2$ test for categorical variables. A $p$-value of $<0.05$ was used to consider differences statistically significant. 
Secondary analysis was performed to ascertain risk factors associated with ICU admission. Since imputation was not feasible as a result of the restricted sample, variables having more than eight missing values were excluded from the regression analysis to guarantee an appropriate number of observations. To evaluate ICU admission prediction performance of sE-selectin levels, a simple logistic regression model was developed and odds ratio, $95 \%$ confidence intervals and receiver operating characteristic (ROC) curves with area under the curve (AUC) were measured. Furthermore, to determine an appropriate cutoff value, we used Youden's Index, grouping sE-selectin levels by two.

We performed a multiple logistic regression model using only statistically significant variables identified with single logistic regression analyses. Finally, $\mathrm{PaO}_{2} / \mathrm{FiO}_{2}$ grouped by two and a value of sE-selectin greater than $33 \mathrm{ng} / \mathrm{mL}$ were selected for the multiple regression model using a stepwise selection procedure. Odds ratios and $95 \%$ confidence intervals $(\mathrm{CI})$ were calculated, although $\mathrm{CI}$ were not reliable since an automated variable selection procedure was used. To assess the model's discriminative ability, accuracy, ROC curve and AUC were measured.

Statistical analyses were performed with $\mathrm{R}$ software version 4.0.0 and RStudio version 1.3.95 (R Core Team (2020). R: A language and environment for statistical computing. $R$ Foundation for Statistical Computing, Vienna, Austria. Available online: https: / / www.Rproject.org/ (accessed on 16 May 2021)).

\section{Results}

\subsection{Patients' Characteristics}

A total of 100 patients with a COVID-19 diagnosis were included in our study. The median age (IQR) was $65(58-78)$ years, $62(62 \%)$ were men. Of these, $29(29 \%)$ were admitted in ICU, $28(28 \%)$ died and $19(19 \%)$ had a thrombotic event. Thrombotic/embolic events included a pulmonary thrombo-embolism $(n=5)$, myocardial infarction $(n=3)$, acute brain ischemia $(n=2)$, acute limb ischemia $(n=7)$ or other $(n=2$, thrombophlebitis, $n=1$ and gonadal vein thrombosis, $n=1$ ). The median value (IQR) of sE-selectin was $26.1 \mathrm{ng} / \mathrm{mL}$ (18.1-35). Median sE-selectin values did not differ between the deceased and survivors (27.1 (22.4-41.7) vs. $25.2(17.1-32.6) \mathrm{ng} / \mathrm{mL}, p=0.06)$ and among patients who experienced a thrombotic event and who did not (32.1 (23.5-39.9) vs. 26.1 (17.5-34.4) ng/mL, $p=0.22)$ (Figure 1A,B). Other baseline characteristics are reported in Table 1.

Table 1. Patient characteristics.

\begin{tabular}{|c|c|c|c|c|}
\hline \multirow{2}{*}{ Characteristics } & \multirow{2}{*}{ Overall, $N=100^{1}$} & \multicolumn{2}{|c|}{ ICU Admission } & \multirow{2}{*}{$p$-Value ${ }^{2}$} \\
\hline & & Non-ICU ${ }^{1}$ & $\mathrm{ICU}^{1}$ & \\
\hline \multicolumn{5}{|c|}{ Demographic } \\
\hline Age (years), median (IQR) & $65(58,78)$ & $64(58,78)$ & $68(58,75)$ & 0.97 \\
\hline Male sex, $n(\%)$ & $62 / 100(62)$ & $38 / 71(54)$ & $24 / 29(83)$ & 0.006 \\
\hline \multicolumn{5}{|c|}{ Comorbidities, $n(\%)$} \\
\hline Diabetes & $18 / 96(19)$ & 13/71 (18) & $5 / 25(20)$ & 0.85 \\
\hline CAD & $13 / 96(14)$ & $9 / 71(13)$ & $4 / 25(16)$ & 0.74 \\
\hline ISH & $42 / 96(44)$ & $31 / 71(44)$ & $11 / 25(44)$ & 0.98 \\
\hline $\mathrm{CHF}$ & $12 / 96(12)$ & $6 / 71(8.5)$ & $6 / 25(24)$ & 0.073 \\
\hline $\mathrm{AF}$ & $6 / 96(6.2)$ & $5 / 71(7.0)$ & $1 / 25(4.0)$ & $>0.99$ \\
\hline PAD & $16 / 96(17)$ & $12 / 71(17)$ & $4 / 25(16)$ & $>0.99$ \\
\hline CVA/TIA & 3/96 (3.1) & $2 / 71(2.8)$ & $1 / 25(4.0)$ & $>0.99$ \\
\hline Dementia & $9 / 95(9.5)$ & $8 / 71(11)$ & $1 / 24(4.2)$ & 0.44 \\
\hline Asthma & $7 / 96(7.3)$ & $6 / 71(8.5)$ & $1 / 25(4.0)$ & 0.67 \\
\hline COPD & $14 / 92(15)$ & $11 / 70(16)$ & $3 / 22(14)$ & $>0.99$ \\
\hline Liver disease & $6 / 96(6.2)$ & $6 / 71(8.5)$ & $0 / 25(0)$ & 0.33 \\
\hline Hemiplegia & $2 / 96(2.1)$ & $1 / 71(1.4)$ & $1 / 25(4.0)$ & 0.46 \\
\hline Solid tumor (last 5 years) & $11 / 92(12)$ & $10 / 70(14)$ & $1 / 22(4.5)$ & 0.29 \\
\hline Leukemia/Lymphoma & $6 / 96(6.2)$ & $5 / 71(7.0)$ & $1 / 25(4.0)$ & $>0.99$ \\
\hline CCI & $4(1,6)$ & $4(1,6)$ & $3(2,4)$ & 0.25 \\
\hline \multicolumn{5}{|c|}{ Onset of symptoms to } \\
\hline $\begin{array}{l}\text { Hospitalization (days), median } \\
\text { (IQR) }\end{array}$ & $6(4,8)$ & $5(3,8)$ & $6(4,8)$ & 0.67 \\
\hline
\end{tabular}


Table 1. Cont.

\begin{tabular}{|c|c|c|c|c|}
\hline Characteristics & Overall, $N=100^{1}$ & \multicolumn{2}{|c|}{ ICU Admission } & $p$-Value ${ }^{2}$ \\
\hline \multicolumn{5}{|c|}{ Signs and symptoms, $n(\%)$} \\
\hline Cough & $52 / 96(54)$ & $38 / 71(54)$ & $14 / 25(56)$ & 0.83 \\
\hline Dyspnea & $48 / 97(49)$ & $30 / 71(42)$ & $18 / 26(69)$ & 0.019 \\
\hline Diarrhea & $11 / 96(11)$ & $10 / 71(14)$ & $1 / 25(4.0)$ & 0.28 \\
\hline Fever & $89 / 98(91)$ & $62 / 71(87)$ & $27 / 27(100)$ & 0.060 \\
\hline Fatigue & $17 / 96(18)$ & $14 / 71(20)$ & $3 / 25(12)$ & 0.55 \\
\hline \multicolumn{5}{|c|}{ Blood gas analysis, median (IQR) } \\
\hline $\mathrm{SpO}_{2}(\%)$ & $96(92,97)$ & $97(94,98)$ & $91(85,97)$ & $<0.001$ \\
\hline $\mathrm{PaO}_{2} / \mathrm{FiO}_{2}$ ratio & $324(242,403)$ & $352(295,424)$ & $185(117,273)$ & $<0.001$ \\
\hline \multicolumn{5}{|c|}{ Laboratory, median (IQR) } \\
\hline WBCs $(\mu \mathrm{L})$ & $5740(4490,8250)$ & $5370(4390,6830)$ & $8790(4915,10,685)$ & 0.005 \\
\hline PMNLs $(\mu \mathrm{L})$ & $4590(2910,6390)$ & $4050(2780,5122)$ & $7560(3768,9840)$ & 0.002 \\
\hline Lymphocytes $(\mu \mathrm{L})$ & $780(560,1140)$ & $800(590,1190)$ & $720(472,982)$ & 0.13 \\
\hline Monocytes $(\mu \mathrm{L})$ & $310(240,425)$ & $310(248,422)$ & $300(230,405)$ & 0.70 \\
\hline $\operatorname{PLT}(\mu \mathrm{L})$ & $187,000(156,000,229,000)$ & $185,000(158,000,228,000)$ & $201,500(146,500,239,750)$ & 0.91 \\
\hline $\mathrm{SCr}(\mathrm{mg} / \mathrm{mL})$ & $0.90(0.80,1.10)$ & $0.90(0.80,1.00)$ & $1.10(0.83,1.30)$ & 0.042 \\
\hline Albumin (g/dL) & $37(32,40)$ & $38(33,41)$ & $34(30,36)$ & 0.008 \\
\hline $\mathrm{LDH}(\mathrm{U} / \mathrm{L})$ & $308(242,404)$ & $284(231,360)$ & $389(274,465)$ & 0.021 \\
\hline D-dimer (ng/mL) & $1366(609,3170)$ & $1180(513,1999)$ & $4474(2516,4610)$ & $<0.001$ \\
\hline \multicolumn{5}{|c|}{ Home therapy, $n(\%)$} \\
\hline ACE-inhibitors/ARBs & $19 / 90(21)$ & $13 / 68(19)$ & $6 / 22(27)$ & 0.42 \\
\hline Diuretics & $17 / 90(19)$ & $12 / 68(18)$ & $5 / 22(23)$ & 0.75 \\
\hline Antiaggregants & $14 / 94(15)$ & $9 / 69(13)$ & $5 / 25(20)$ & 0.51 \\
\hline Anticoagulants & $4 / 94(4.3)$ & $3 / 69(4.3)$ & $1 / 25(4.0)$ & $>0.99$ \\
\hline Statins & $12 / 90(13)$ & $9 / 68(13)$ & $3 / 22(14)$ & $>0.99$ \\
\hline \multicolumn{5}{|c|}{ Outcomes, $n(\%)$} \\
\hline Death & $28 / 100(28)$ & $8 / 71(11)$ & $20 / 29(69)$ & $<0.001$ \\
\hline Thrombotic event & $19 / 100(19)$ & $7 / 71(9.9)$ & $12 / 29(41)$ & $<0.001$ \\
\hline \multicolumn{5}{|c|}{ Markers, median (IQR) } \\
\hline sE-selectin (ng/mL) & $\begin{array}{c}26.1 \\
(18.1,35.0)\end{array}$ & $\begin{array}{c}24.1 \\
(17.0,30.1)\end{array}$ & $\begin{array}{c}36.6 \\
(25.8,47.1)\end{array}$ & $<0.001$ \\
\hline
\end{tabular}

${ }^{1}$ Median (IQR) or Frequency (\%). ${ }^{2}$ Wilcoxon rank sum test; Pearson's Chi-squared test. ICU: intensive care unit; CAD, coronary artery disease; ISH, isolated systolic hypertension; $\mathrm{CHF}$, chronic heart failure; AF, atrial fibrillation; PAD, peripheral artery disease; CVA/TIA, cerebral vascular accident/transient ischemic attack; COPD, chronic obstructive pulmonary disease; CCI, Charlson comorbidity index; WBCs, white blood cells; PMNLs, polymorphonuclear leukocytes; PLTs, platelets; SCr, serum creatinine; LDH, lactate dehydrogenase; ARBs, angiotensin receptor blockers.

\subsection{Comparison between ICU and Non-ICU-Admitted Patients}

The between-group differences among ICU-admitted and non-ICU-admitted patients are shown in Table 1. No differences in age, lymphocytes, monocytes and platelets count, fibrinogen, comorbidities prevalence, Charlson Comorbidity Index and use of ACE inhibitors, angiotensin receptors blockers (ARBs), diuretics, antiaggregants, anticoagulants and statins were found to be statistically significant. On the other hand, sE-selectin levels, male sex, the peripheral saturation of oxygen, $\mathrm{PaO}_{2} / \mathrm{FiO}_{2}$ ratio, white blood cells count, polymorphonuclear neutrophils count, serum creatinine values, albumin, lactate dehydrogenase (LDH) and D-dimer levels were significantly different between the two groups. Compared with patients who did not receive intensive care treatments, patients requiring ICU care had higher levels of sE-selectin (36.6 (25.8-47.1) vs. 24.1 (17.0-30.1) ng/mL; $p<0.001$ ) (Figure 1C).

\section{3. sE-Selectin for Prediction of ICU Admission}

A simple logistic regression model with sE-selectin levels as the predictor of ICU admission was developed. Each increment of $1 \mathrm{ng} / \mathrm{mL}$ of sE-selectin level was associated with a higher risk of ICU care with an odds ratio of 1.07 ( $95 \%$ CI, 1.03 to 1.12) (Table 2). The AUC of the ROC curve was 0.75 (95\% CI, 0.64 to 0.87 ). The ROC curve for the differentiation of ICU-admitted from non-admitted patients, the respective AUC and test performance of sE-selectin for prediction are shown in Tables 2 and 3, respectively. 
(A)

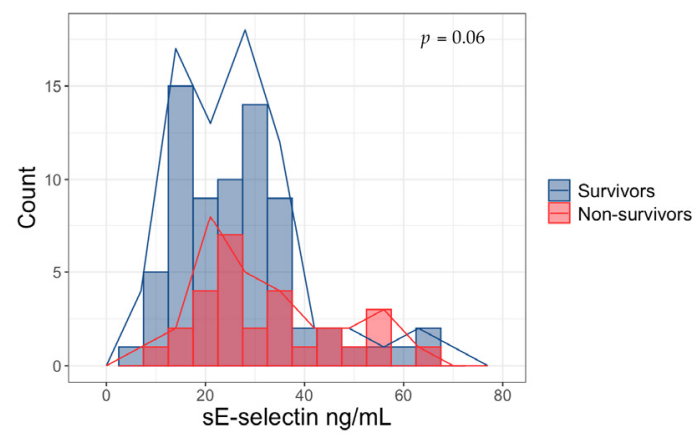

(C)

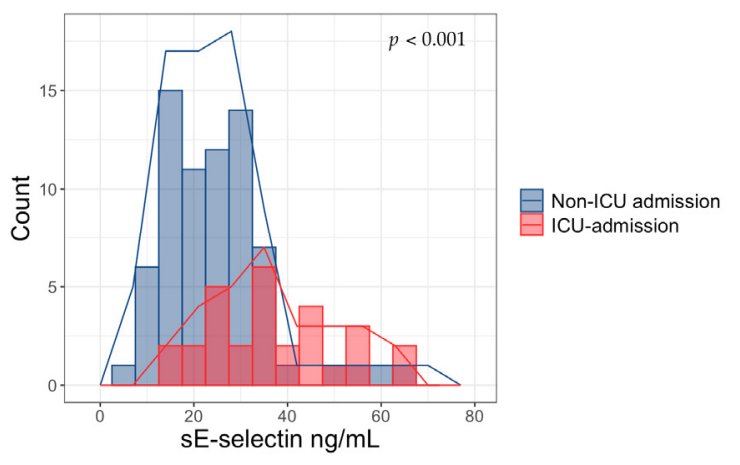

(B)

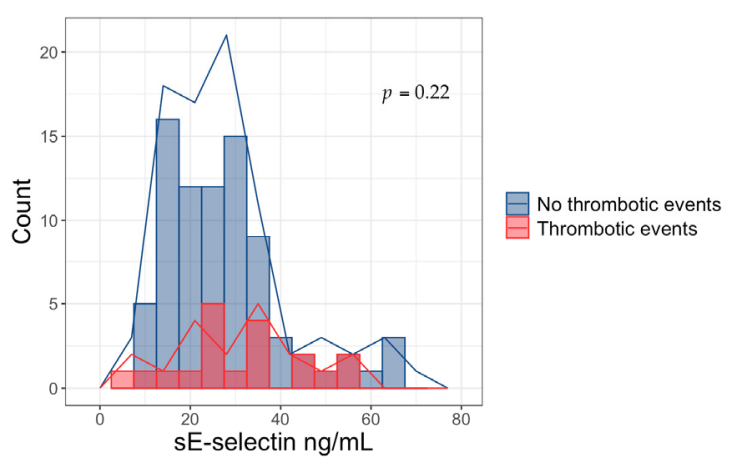

Figure 1. Serum E-selectin levels in non-survivors and survivors (A), in patients with thrombotic events and those without thrombotic events (B) and in ICU and non-ICU-admitted patients (C). ICU: intensive care unit.

Table 2. sE-selectin as predictor of ICU admission from Simple Logistic Regression.

\begin{tabular}{cccc}
\hline \multicolumn{5}{c}{ Analysis } \\
\hline Characteristic & OR $^{\mathbf{1}}$ & $\mathbf{9 5 \%} \mathbf{C I}^{\mathbf{1}}$ & $p$-Value \\
\hline sE-selectin & 1.07 & $1.03,1.12$ & $<0.001$ \\
\hline
\end{tabular}

${ }^{1}$ OR: odds ratio; CI: confidence interval; ICU: intensive care unit.

Table 3. Test performance of sE-selectin for prediction of ICU admission.

\begin{tabular}{ccccc}
\hline Prediction & Optimal Cutoff $^{\mathbf{1}}(\mathbf{n g} / \mathbf{m L})$ & Se & Sp & Acc \\
\hline ICU vs. Non-ICU & 32.7 & 0.61 & 0.83 & 0.77
\end{tabular}

${ }^{1}$ Optimal cutoff values derived from receiver operating characteristics by Youden's index and sensitivity (Se), specificity (Sp) and Accuracy (Acc) from the resulting $2 \times 2$ tables. ICU: intensive care unit.

\subsection{Multiple Logistic Regression Analysis}

A multiple logistic regression model using a stepwise selection procedure was calculated. Odds ratios and 95\% confidence intervals of both univariate and multivariate models are reported in Table 4. A value of sE-selectin levels greater than $33 \mathrm{ng} / \mathrm{mL}$ (OR 13.7 (95\% CI, 3.2 to 81.9)), a $\mathrm{PaO}_{2} / \mathrm{FiO}_{2}$ ratio below 200 (OR 80.3 (95\% CI, 14.4 to 716.2 )) and $\mathrm{PaO}_{2} / \mathrm{FiO}_{2}$ ratio between 200 and 300 (OR 9.1 (95\% CI, 1.7 to 62.1)) were found to be significantly associated with an increased risk of ICU admission, after being adjusted for sex, LDH levels and the absolute neutrophil count. The resulting AUC of the ROC curve was 0.90 (95\% CI, 0.83 to 0.98 ) (Figure 2). 


\subsection{Correlation Analyses}

Correlation coefficients of variables included in the multiple regression model were calculated. Values of sE-selectin significantly correlated with the neutrophils count with a coefficient of $0.32(p=0.001)$ (Figure 3A). In addition, a positive correlation between sE-selectin values and the number of days from the symptoms onset to hospitalization was found with a correlation coefficient of $0.28(p=0.004)$ (Figure 3B). Although not significantly, sE-selectin positively correlated with D-dimer levels (coefficient $0.17, p=0.08$ ).

Table 4. Risk factors associated with ICU admission.

\begin{tabular}{ccccccc}
\hline Characteristic. & OR ${ }^{\mathbf{1}}$ & $\begin{array}{c}\text { Univariable } \\
\mathbf{9 5 \%} \mathbf{C I}^{\mathbf{1}}\end{array}$ & $\boldsymbol{p}$-Value & $\mathbf{O R}^{\mathbf{1}}$ & $\begin{array}{c}\text { Multivariable } \\
\mathbf{9 5 \%} \mathbf{C I}^{\mathbf{1}}\end{array}$ & $\boldsymbol{p}$-Value \\
\hline Male Sex & 4.11 & $1.37-15.3$ & 0.019 & & & \\
$\mathrm{PMNL}>8000 / \mu \mathrm{L}$ & 12.5 & $3.61-51.6$ & $<0.001$ & & & \\
$\mathrm{LDH}>300 \mathrm{U} / \mathrm{L}$ & 2.64 & $1.00-7.63$ & 0.058 & & & \\
$\mathrm{sE-selectin}>33 \mathrm{ng} / \mathrm{mL}$ & 7.39 & $2.66-21.8$ & $<0.001$ & 13.7 & $3.25-82.0$ & 0.001 \\
$\mathrm{PaO}_{2} / \mathrm{FiO}_{2}$ ratio & & & & & & \\
$200-300$ & 7.14 & $1.67-37.4$ & 0.011 & 9.08 & $1.74-62.1$ & 0.013 \\
$<200$ & 46.7 & $11.2-264$ & $<0.001$ & 80.3 & $14.4-716$ & $<0.001$ \\
\hline
\end{tabular}

${ }^{1}$ OR: odds ratio; CI: confidence interval; ICU: intensive care unit; PMNL: polymorphonuclear leukocytes; LDH: lactate dehydrogenase.

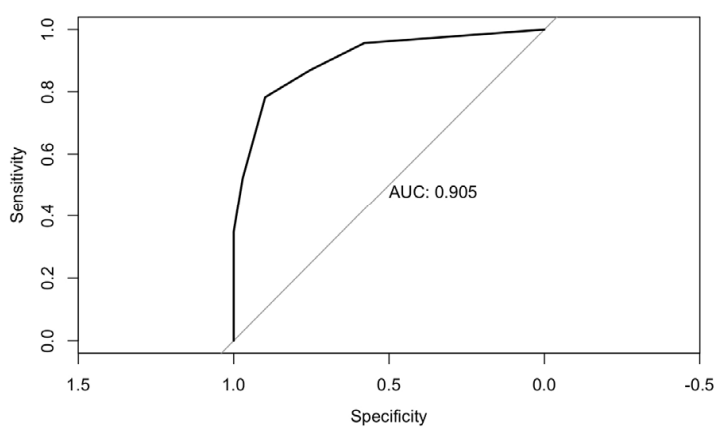

Figure 2. ROC curve of multiple logistic regression model using sE-selectin $>33 \mathrm{ng} / \mathrm{mL}, \mathrm{PaO}_{2} / \mathrm{FiO}_{2}$ 200-300 and $\mathrm{PaO}_{2} / \mathrm{FiO}_{2}<200$ as predictors of Intensive Care Unit (ICU) admission.

(A)

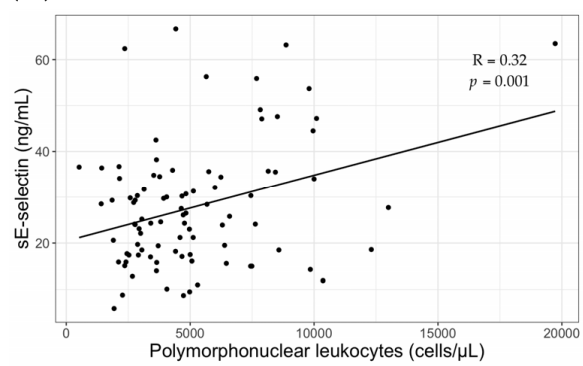

(B)

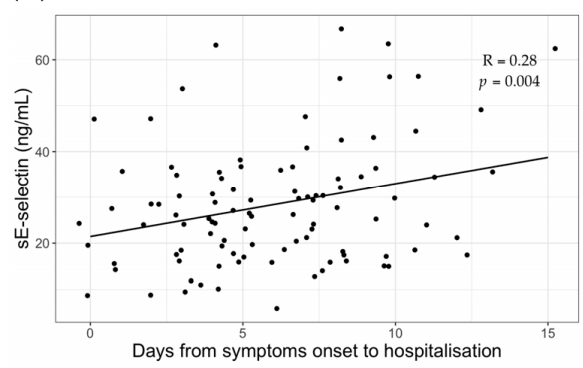

Figure 3. Correlation analyses of sE-selectin with polymorphonuclear leukocytes count (A) and days from symptoms onset to hospitalization (B). 


\section{Discussion}

This study showed that sE-selectin levels are predictive of ICU admission in COVID-19 patients, providing a possible biomarker to determine the severity of the disease. Indeed, compared to patients who did not require intensive care treatment, the results demonstrated higher levels of sE-selectin in ICU-admitted patients. The $\mathrm{sE}$-selectin (Endothelial Leukocytes Adhesion Molecule (1) is a soluble adhesion molecule synthetized by activated endothelium, known to have pro-thrombotic effects involved in coagulopathy $[9,14]$. Thrombotic complications are frequent during the course of the disease contributing to its morbidity and mortality $[15,16]$ and several mechanisms have been studied as a cause of these phenomena [17-20]. Vascular inflammation and endothelial activation have been related to the spectrum of COVID-19-associated coagulopathy [5]. Furthermore, among others, the role of sE-selectin as a marker of endothelial dysfunction, inflammation or damage, points out the central role of the endothelium itself not only in the development of a more severe form of the disease, but also in the pathogenesis of the cardiovascular events that occur during COVID-19, including immuno-thrombosis and arrhythmias [6]. As a matter of fact, the inflammatory milieu as a consequence of the so-called 'cytokine storm' may contribute to the progression of endothelial damage, which, in turn, amplifies the pro-inflammatory and pro-coagulant processes [21] as well as the high production of reactive oxygen species [18], all conditions observed during severe COVID-19.

Among patients admitted in the intensive care unit sE-selectin levels were significantly higher. This finding was not surprising since endothelial activation may reflect a more severe form of the disease, possibly leading to ICU admission. So far, only a few studies investigated the prognostic effect of sE-selectin as a marker of disease severity or mortality in COVID-19 patients [21-23], although with non-univocal results [24]. In fact, similarly to our results, Smadja and colleagues showed that sE-selectin at hospital admission was a discriminant biomarker for ICU admission [22]; likewise, Vassiliou et al. found that, amongst several markers of endothelial damage, sE-selectin was significantly elevated in ICU non-survivors compared to survivors, possibly predicting mortality in critically ill COVID-19 patients [23]. More recently, Birnhuber et al. showed significantly higher levels of sE-selectin in critically ill COVID-19 patients than healthy controls [21]. On the other hand, Spadaro and co-authors found that sE-selectin plasma levels did not differ between COVID-19 non-survivor and survivor patients with acute respiratory distress syndrome [24]. All in all, while the majority of the aforementioned studies converged with the concept that endothelial cell activation and dysregulation occur in COVID-19 and that markers of endothelial activation may have a prognostic role during the disease, still definite evidence is lacking.

Hence, our results may provide additional insights into the pathogenesis of COVID-19 and its clinical implications.

It is also worth noticing that, although we did not find a significant difference between patients with and without thrombotic events, the median values tended to diverge (32.1 ng/mL vs. $26.1 \mathrm{ng} / \mathrm{mL}$ ). The observed difference in sE-selectin values between subjects experiencing — or not - a thrombotic event may be a reflection of the pathophysiologic role of E-selectin in SARS-CoV-2 infection and may explain the high incidence of thrombosis in some patients in the clinical practice. Moreover, we found a positive correlation between neutrophils and sE-selectin values. The polymorphonuclear leukocyte activation in severe infections can lead to neutrophil extracellular traps (NET) formation [25]. NETs are web-like chromatin structures involved in the immune and anti-infective response [26,27]; their role in viral infections has already been investigated for Influenza and Respiratory syncytial virus (RSV) and consists of inhibiting viral replication and aggregation [28,29]. However, when NETs are excessively released, their activation might have detrimental effects to the host, being linked to endothelial cell injury [30-32]. Thus, our result could be explained by the detrimental effects of NETs on the endothelium in SARS-CoV-2 severe infection leading to its higher expression and participation in vascular damage, as illustrated in previous articles [33-35]. Finally, we showed that time from the symptoms 
onset to hospitalization significantly correlates with sE-selectin, highlighting a plausible relation between endothelium activation and disease progression. Nevertheless, our study should be interpreted considering several limitations. First, it was a retrospective study having the shortcomings of similar researches. Second, data were collected during the first months of the pandemic, possibly resulting in conclusions not completely reliable in the present phase, where the approach to COVID-19 is more solid and established. Third, the sample size was likely not large enough to catch important difference in outcomes, including death and thrombotic events, especially the latter, since sE-selectin distributions seemed to be different in the two groups despite not reaching a statistical significance. Fourth, we only dosed serum E-selectin at the beginning of the disease and not during its course. Indeed, we were not able to evaluate the possible influence of anticoagulation on sE-selectin levels and, consequently, to investigate in depth the relation between sE-selectin, the use of anticoagulants and thrombosis development.

Except for the mentioned limitations, data on the relation between sE-selectin and COVID-19 as well as studies exploring the linkage between blood cells and the disease are scarce. As such, this study aimed to contribute toward the comprehension of pathogenic aspects of the illness, giving a possible clinical marker able to predict its severity. However, further studies are crucial to clarify the ample aspects of COVID-19 pathogenesis.

Author Contributions: Study concept and design, A.O.; acquisition of data, F.C., R.A. and V.M.; performing experiments, M.C.M., F.D.T., M.D.A. and D.A.I.; analysis and interpretation of data, E.R. and A.O.; drafting of the manuscript, E.R.; critical revision of the manuscript for important intellectual content, A.O.; statistical analysis, E.R.; study supervision, L.L. and C.M.M. All authors have read and agreed to the published version of the manuscript.

Funding: This research received no external funding.

Institutional Review Board Statement: The study was conducted according to the guidelines of the Declaration of Helsinki and approved by the local Institutional Review Board. The study protocol was approved by the local Ethics Committee (ID Prot. 298/2020).

Informed Consent Statement: Informed consent was obtained from all subjects involved in the study.

Data Availability Statement: All data relevant to the study is included in the article and is available from the corresponding author upon request.

Acknowledgments: Authors thank the nurse staff for their contribution in sample collection.

Conflicts of Interest: The authors declare no conflict of interest.

\section{References}

1. Zhu, N.; Zhang, D.; Wang, W.; Li, X.; Yang, B.; Song, J.; Zhao, X.; Huang, B.; Shi, W.; Lu, R.; et al. A Novel Coronavirus from Patients with Pneumonia in China, 2019. New Engl. J. Med. 2020, 382, 727-733. [CrossRef]

2. Gandhi, R.T.; Lynch, J.B.; Del Rio, C. Mild or moderate Covid-19. N. Engl. J. Med. 2020, 383, 1757-1766. [CrossRef]

3. Richardson, S.; Hirsch, J.S.; Narasimhan, M.; Crawford, J.M.; McGinn, T.; Davidson, K.W.; Barnaby, D.P.; Becker, L.B.; Chelico, J.D.; Cohen, S.L.; et al. Presenting Characteristics, Comorbidities, and Outcomes Among 5700 Patients Hospitalized With COVID-19 in the New York City Area. JAMA 2020, 323, 2052-2059. [CrossRef] [PubMed]

4. Helms, J.; CRICS TRIGGERSEP Group (Clinical Research in Intensive Care and Sepsis Trial Group for Global Evaluation and Research in Sepsis); Tacquard, C.; Severac, F.; Leonard-Lorant, I.; Ohana, M.; Delabranche, X.; Merdji, H.; Clere-Jehl, R.; Schenck, M.; et al. High risk of thrombosis in patients with severe SARS-CoV-2 infection: A multicenter prospective cohort study. Intensiv. Care Med. 2020, 46, 1089-1098. [CrossRef] [PubMed]

5. Zhang, J.; Tecson, K.M.; McCullough, P.A. Endothelial dysfunction contributes to COVID-19-associated vascular inflammation and coagulopathy. Rev. Cardiovasc. Med. 2020, 21, 315-319. [CrossRef] [PubMed]

6. Oliva, A.; Franchi, C.; Gatto, M.C.; Galardo, G.; Pugliese, F.; Mastroianni, C. Prevalence and clinical significance of relative bradycardia at hospital admission in patients with coronavirus disease 2019 (COVID-19). Clin. Microbiol. Infect. 2021, 27, 1185-1187. [CrossRef] [PubMed]

7. Iba, T.; Connors, J.M.; Levy, J.H. The coagulopathy, endotheliopathy, and vasculitis of COVID-19. Inflamm. Res. 2020, 69, 1181-1189. [CrossRef] 
8. Silva, M.; Videira, P.A.; Sackstein, R. E-selectin ligands in the human mononuclear phagocyte system: Implications for infection, inflammation, and immunotherapy. Front. Immunol. 2018, 8, 1878. [CrossRef]

9. Roldán, V.; Marín, F.; Lip, G.Y.; Blann, A.D. Soluble E-selectin in cardiovascular disease and its risk factors. A review of the literature. Thromb. Haemost. 2003, 90, 1007-1020. [CrossRef]

10. Konstantinides, S.V.; Meyer, G.; Becattini, C.; Bueno, H.; Geersing, G.-J.; Harjola, V.-P.; Huisman, M.V.; Humbert, M.; Jennings, C.S.; Jiménez, D.; et al. 2019 ESC Guidelines for the diagnosis and management of acute pulmonary embolism developed in collaboration with the European Respiratory Society (ERS). Eur. Heart J. 2020, 41, 543-603. [CrossRef]

11. Thygesen, K.; Alpert, J.S.; Jaffe, A.S.; Chaitman, B.R.; Bax, J.J.; Morrow, D.A.; White, H.D.; The Executive Group on behalf of the Joint European Society of Cardiology (ESC)/American College of Cardiology (ACC)/American Heart Association (AHA)/World Heart Federation (WHF) Task Force for the Universal Definition of Myocardial Infarction. Fourth Universal Definition of Myocardial Infarction (2018). J. Am. Coll. Cardiol. 2018, 138, e618-e651. [CrossRef]

12. Kernan, W.N.; Ovbiagele, B.; Black, H.R.; Bravata, D.M.; Chimowitz, M.I.; Ezekowitz, M.D.; Fang, M.C.; Fisher, M.; Furie, K.L.; Heck, D.V.; et al. Guidelines for the Prevention of Stroke in Patients With Stroke and Transient Ischemic Attack. Stroke 2014, 45, 2160-2236. [CrossRef]

13. Bonaca, M.P.; Gutierrez, J.A.; Creager, M.A.; Scirica, B.M.; Olin, J.; Murphy, S.A.; Braunwald, E.; Morrow, D.A. Acute Limb Ischemia and Outcomes With Vorapaxar in Patients With Peripheral Artery Disease. Circulation 2016, 133, 997-1005. [CrossRef]

14. Zhang, J.; Defelice, A.F.; Hanig, J.P.; Colatsky, T. Biomarkers of endothelial cell activation serve as potential surrogate markers for drug-induced vascular injury. Toxicol. Pathol. 2010, 38, 856-871. [CrossRef]

15. Hanff, T.C.; Mohareb, A.M.; Giri, J.; Cohen, J.B.; Chirinos, J.A. Thrombosis in COVID-19. Am. J. Hematol. 2020, 95, 1578-1589. [CrossRef] [PubMed]

16. Violi, F.; Ceccarelli, G.; Cangemi, R.; Cipollone, F.; D’Ardes, D.; Oliva, A.; Pirro, M.; Rocco, M.; Alessandri, F.; D’Ettorre, G.; et al. Arterial and venous thrombosis in coronavirus 2019 disease (Covid-19): Relationship with mortality. Intern. Emerg. Med. 2021, 16, 1231-1237. [CrossRef] [PubMed]

17. Oliva, A.; Cammisotto, V.; Cangemi, R.; Ferro, D.; Miele, M.C.; De Angelis, M.; Cancelli, F.; Pignatelli, P.; Venditti, M.; Pugliese, F.; et al. Low-Grade Endotoxemia and Thrombosis in COVID-19. Clin. Transl. Gastroenterol. 2021, 12, e00348. [CrossRef] [PubMed]

18. Violi, F.; Oliva, A.; Cangemi, R.; Ceccarelli, G.; Pignatelli, P.; Carnevale, R.; Cammisotto, V.; Lichtner, M.; Alessandri, F.; De Angelis, M.; et al. Nox2 activation in Covid-19. Redox Biol. 2020, 36, 101655. [CrossRef]

19. Violi, F.; Ceccarelli, G.; Cangemi, R.; Alessandri, F.; D’Ettorre, G.; Oliva, A.; Pastori, D.; Loffredo, L.; Pignatelli, P.; Ruberto, F.; et al. Hypoalbuminemia, Coagulopathy, and Vascular Disease in COVID-19. Circ. Res. 2020, 127, 400-401. [CrossRef]

20. Colling, M.E.; Kanthi, Y. COVID-19-associated coagulopathy: An exploration of mechanisms. Vasc. Med. 2020, 25, 471-478. [CrossRef]

21. Birnhuber, A.; Fliesser, E.; Gorkiewicz, G.; Zacharias, M.; Seeliger, B.; David, S.; Welte, T.; Schmidt, J.; Olschewski, H.; Wygrecka, M.; et al. Between inflammation and thrombosis-Endothelial cells in COVID-19. Eur. Respir. J. 2021, 13, 2100377. [CrossRef] [PubMed]

22. Smadja, D.M.; Guerin, C.L.; Chocron, R.; Yatim, N.; Boussier, J.; Gendron, N.; Khider, L.; Hadjadj, J.; Goudot, G.; Debuc, B.; et al. Angiopoietin-2 as a marker of endothelial activation is a good predictor factor for intensive care unit admission of COVID-19 patients. Angiogenesis 2020, 23, 611-620. [CrossRef] [PubMed]

23. Vassiliou, A.; Keskinidou, C.; Jahaj, E.; Gallos, P.; Dimopoulou, I.; Kotanidou, A.; Orfanos, S. ICU Admission Levels of Endothelial Biomarkers as Predictors of Mortality in Critically Ill COVID-19 Patients. Cells 2021, 10, 186. [CrossRef] [PubMed]

24. Spadaro, S.; Fogagnolo, A.; Campo, G.; Zucchetti, O.; Verri, M.; Ottaviani, I.; Tunstall, T.; Grasso, S.; Scaramuzzo, V.; Murgolo, F.; et al. Markers of endothelial and epithelial pulmonary injury in mechanically ventilated COVID-19 ICU patients. Crit. Care 2021, 25, 1-9. [CrossRef] [PubMed]

25. Rosazza, T.; Warner, J.; Sollberger, G. NET formation-Mechanisms and how they relate to other cell death pathways. FEBS J. 2021, 288, 3334-3350. [CrossRef]

26. Papayannopoulos, V. Neutrophil extracellular traps in immunity and disease. Nat. Rev. Immunol. 2018, 18, 134-147. [CrossRef]

27. Mutua, V.; Gershwin, L.J. A review of Neutrophil Extracellular Traps (NETs) in disease: Potential Anti-NETs therapeutics. Clin. Rev. Allergy Immunol. 2020, 61, 1-18. [CrossRef]

28. Hoeksema, M.; Tripathi, S.; White, M.; Qi, L.; Taubenberger, J.; van Eijk, M.; Haagsman, H.; Hartshorn, K.L. Arginine-rich histones have strong antiviral activity for influenza A viruses. Innate Immun. 2015, 21, 736-745. [CrossRef]

29. Narasaraju, T.; Yang, E.; Samy, R.P.; Ng, H.H.; Poh, W.P.; Liew, A.-A.; Phoon, M.C.; van Rooijen, N.; Chow, V.T. Excessive Neutrophils and Neutrophil Extracellular Traps Contribute to Acute Lung Injury of Influenza Pneumonitis. Am. J. Pathol. 2011, 179, 199-210. [CrossRef]

30. Vogel, S.; Bodenstein, R.; Chen, Q.; Feil, S.; Feil, R.; Rheinlaender, J.; Schäffer, T.; Bohn, E.; Frick, J.-S.; Borst, O.; et al. Plateletderived HMGB1 is a critical mediator of thrombosis. J. Clin. Investig. 2015, 125, 4638-4654. [CrossRef]

31. Cheng, O.Z.; Palaniyar, N. NET balancing: A problem in inflammatory lung diseases. Front. Immunol. 2013, 4, 1. [CrossRef] [PubMed] 
32. Saffarzadeh, M.; Juenemann, C.; Queisser, M.A.; Lochnit, G.; Barreto, G.; Galuska, S.P.; Lohmeyer, J.; Preissner, K.T. Neutrophil Extracellular Traps Directly Induce Epithelial and Endothelial Cell Death: A Predominant Role of Histones. PLoS ONE 2012, 7, e32366. [CrossRef] [PubMed]

33. Radermecker, C.; Detrembleur, N.; Guiot, J.; Cavalier, E.; Henket, M.; D’Emal, C.; Vanwinge, C.; Cataldo, D.; Oury, C.; Delvenne, P.; et al. Neutrophil extracellular traps infiltrate the lung airway, interstitial, and vascular compartments in severe COVID-19. J. Exp. Med. 2020, 217. [CrossRef]

34. Thierry, A.R.; Roch, B. Neutrophil extracellular traps and by-products play a key role in COVID-19: Pathogenesis, risk factors, and therapy. J. Clin. Med. 2020, 9, 2942. [CrossRef]

35. Veras, F.P.; Pontelli, M.C.; Silva, C.M.; Toller-Kawahisa, J.E.; de Lima, M.; Nascimento, D.C.; Schneider, A.H.; Caetité, D.; Tavares, L.A.; Paiva, I.M.; et al. SARS-CoV-2-triggered neutrophil extracellular traps mediate COVID-19 pathology. J. Exp. Med. 2020, 217, e20201129. [CrossRef] [PubMed] 